\title{
Applicability of Different Bio-based Polymers for Wiring Boards
}

\author{
Carolin Henning ${ }^{1 *}$, Anna Schmid ${ }^{2}$, Sophia Hecht ${ }^{2}$, Kathrin Harre², Reinhard Bauer ${ }^{1}$ \\ ${ }^{1}$ Faculty of Electrical Engineering, University of Applied Sciences Dresden, PF 120701, D-01008 Dresden, Germany \\ 2 Faculty of Agriculture, Environment, Chemistry, University of Applied Sciences Dresden, PF 120701, D-01008 Dresden, Germany \\ ${ }^{*}$ Corresponding author, e-mail: carolin.henning@htw-dresden.de
}

Received: 09 November 2018, Accepted: 22 November 2018, Published online: 15 February 2019

\begin{abstract}
The paper gives a review of experiments for the application of biodegradable, sustainable polymers as a wiring board material. In the paper two different biobased materials and the standard PCB materials FR4 and FR2 were compared. The investigations refer to mechanical, electrical performance, surface quality, flammability and applicability for Polymer Thick Film Technology (PTFT) of the biobased material. The biobased materials are polylactic acid (PLA) mixed with different contents of cellulose acetate (CA) or flame retardant zinc pyrophosphate (ZnPP) and polyurethane (PU) with CA. The results show that the addition of CA to the polymers leads to a change of different properties for PLA and to a significant change in mechanical properties for PU. The use of ZnPP in PLA shows major improvements regarding the flammability of the polymer. The properties of the samples are in the same order of magnitude as the properties of FR2.
\end{abstract}

Keywords

Eco-Electronics, polyurethane, polylactic acid, wiring board

\section{Introduction}

The electronic waste problem is becoming more and more important. The amount of produced electronics, e-waste and also the increasingly short life of electronics contribute to the waste problem. Therefore a possibility to recycle should have been detected. The recyclability is the ability of a material to be captured and separated from a waste stream for conversion or reuse. The standard material is not recyclable due to the flame retardant polybrominated diphenyl ethers. Because of the recyclability or the degradability, the investigations of bio-based wiring board materials are important and could be an alternative for FR4. Biobased materials are materials derived from biological or renewable resources and offer the possibility for recycling. Polylactic acid (PLA) could be a good alternative, because of the good characteristics, great chemical versatility and is counted among the renewable resources. It offers also the possibility of biodegradation. Biodegradation is the ability to breake materials into basic components e.g. carbondioxide or methane [1]. Our previous work focused on PLA with different contents of cellulose acetate (CA) and aluminum polyphosphate and found out that it is critical to use conductive pastes because of the thermal stress [2, 3]. Géczy et al.
[4] investigated the mechanical performance of pure PLA and cellulose acetate. They found out that both materials act weaker than standard materials and that additives are needed to improve the mechanical performance. Mattana et al. [5] investigated the use of PLA in organic electronic devices and for sensor applications [6]. It was also investigated that PLA can be used as a substrate material for antennas for $2.45 \mathrm{GHz}$ ISM [7]. Oi et al. [8] increase the crystallinity of PLA from $6 \%$ to $42 \%$ by performing a heat-treatment of PLA before the application to reduce the problem of thermal stress for PLA. The effects of a decreasing crystallinity of PLA due to increased temperature have been investigated as well $[9,10]$. Different additives were tested to improve the properties of PLA [11]. Jute fibers were used to improve the mechanical properties. Kenaf, cellulose and wood fibers were tested as well [12, 13]. As a possible halogen free alternative different phosphorus based flame retardants like aluminum polyphosphate have been tested $[11,14]$.

In the present paper another partially renewable material was tested. Polyurethane (PU) could also an alternative for wiring board material. In this case renewable 
means the relation to a natural resource and the use of raw materials that are produced from regrowing substances. The main concern of those biopolymers is to improve their characteristic profile to reach that of standard materials. Like Géczy et al. [4] stated PLA has to be modified with additives. Therefore this paper deals with PLA mixed with different contents of cellulose acetate and zinc pyrophoshate $(\mathrm{ZnPP})$. Zinc pyrophosphate $(\mathrm{ZnPP})$ is a halogen free alternative flame retardant [15].

The paper shows an overview of the mechanical and electrical performances of PLA/CA and PU/CA compounds in reference to wiring board materials. The present paper deals with production, processing and application of these bio-based materials.

\section{Method and materials}

\subsection{Investigation strategies}

Previous studies showed that PLA is a suitable material for wiring boards in limited applications. PLA can be obtained from renewable resources. Certain additives, like fillers or flame retardants, have different effects on the properties of PLA. In this study CA fibers were used as a filler material to improve the mechanical properties of PLA. To improve PLA's flame behavior ZnPP as a flame retardant was added. Because of the relatively low glass transistion temperature of PLA it's applicability is still limited. A different biopolymer partially based on renewable resources was produced and characterized [16]. The comparison of different properties of PLA composites and $\mathrm{PU}$ composites is shown in the following paper.

\subsection{Material and variations}

The PLA used was supplied by NatureWorks (USA) under the trade name Ingeo ${ }^{\text {TM }}$ Biopolymer 3251D. The CA (CA398-30) used was supplied by Eastman Chemical Company (USA). The zinc pyrophosphate is found as Budit 3178 and was supplied by Budenheim Ibérica S.L.U. (Spain). For the PU synthesis the bio based polyether polyol Lupranol/2005/1/Balance from Basf SE (Germany) was used. TIB KAT 218 from TIB Chemicals (Germany) was used as a catalyst. 1,4 Butandiol was supplied by KMF Laborchmie Handels GmbH (Germany) and dried over molecular sieves $3 \AA$ before use. Basonat $\mathrm{H}$ (hexamethylene diisocyanat) was supplied by Basf SE (Germany).

The sample preparation of the PLA composites took place via melt compounding. For this PLA pellets were inserted in a stainless steel bowl on a hot plate with a thermostat. The PLA pellets were continuously stirred and melted. The required amounts of $\mathrm{CA}$ or $\mathrm{ZnPP}$ were added to the melted PLA while stirring continued. After reaching a sufficient homogeneity of the melted composite material, it was transferred on a PTFE mould to cool down. To shape the composites the material was melted in a silicone mould in an oven with recirculating air.

The preparation of the PU samples took place via a one shot process. The Polyol, the chain extender Butandiol and the catalyst dibutyl tin dilaurate were carefully mixed in a stainless steel cup. The required amount of CA was carefulled stirred in the mixture. The mixture was tempered at $85^{\circ} \mathrm{C}$ and 500 mbar for $1 \mathrm{~h}$ in a vacuum drying oven. The required amounts of isocyanate were carefully added to the mixture. The mixture was stirred and transferred into a silicon mould. It was cured at $85^{\circ} \mathrm{C}$ for $24 \mathrm{~h}$. The surface of the samples was grinded down to receive a level surface with the polishing machine from Struers RotoPol-31 and RotoForce- 4 with a grain size of 120 , a force of $100 \mathrm{~N}$ and $300 \mathrm{rpm}$. Table 1-3 show the compositions of the samples.

\subsection{Surface energy}

A different method to gain knowledge of the adhesion on a printable surface is the wettability. By measuring the contact angle of a liquid on the surface of the sample

Table 1 Composition of the PLA/CA samples

\begin{tabular}{lcc}
\hline Sample & PLA $[\mathrm{g}]$ & CA $[\mathrm{g}]$ \\
\hline PLA/CA1 & 100 & 1 \\
PLA/CA2,5 & 100 & 2.5 \\
PLA/CA5 & 100 & 5 \\
PLA/CA10 & 100 & 10 \\
PLA/CA15 & 100 & 15 \\
PLA/CA20 & 100 & 20 \\
PLA/CA25 & 100 & 25 \\
PLA/CA30 & 100 & 30 \\
PLA/CA35 & 100 & 35 \\
PLA/CA40 & 100 & 40 \\
\hline \multicolumn{1}{c}{ Table 2 Composition of the PLA/ZnPP samples } \\
\hline Sample & PLA [g] & ZnPP [g] \\
\hline PLA/ZnPP1 & 100 & 1 \\
PLA/ZnPP5 & 100 & 5 \\
PLA/ZnPP10 & 100 & 10 \\
PLA/ZnPP15 & 100 & 25 \\
PLA/ZnPP20 & 100 & 30 \\
PLA/ZnPP25 & 100 & 15 \\
\hline PLA/ZnPP30 & & 200 \\
\hline
\end{tabular}


Table 3 Composition of the PU samples with the weight of the different components

\begin{tabular}{lcccc}
\hline \multirow{2}{*}{ Sample } & \multicolumn{4}{c}{ Component weight $[\mathrm{g}]$} \\
\cline { 2 - 5 } & Polyol & Butandiol & CA & Basonat H \\
\hline PU & 35 & 2.19 & 0 & 7.40 \\
PU/CA5 & 35 & 2.19 & 1.86 & 7.75 \\
PU/CA10 & 35 & 2.19 & 3.72 & 8.10 \\
PU/CA15 & 35 & 2.19 & 5.58 & 8.46 \\
PU/CA20 & 35 & 2.19 & 7.44 & 8.81 \\
PU/CA25 & 35 & 2.19 & 9.30 & 9.71 \\
PU/CA30 & 35 & 2.19 & 11.16 & 9.52 \\
PU/CA35 & 35 & 2.19 & 13.02 & 9.88 \\
PU/CA40 & 35 & 2.19 & 14.88 & 10.23 \\
\hline
\end{tabular}

material, the surface energy of the material can be calculated. According to the Owens, Wendt, Tabel and Kaelble (OWRK) theory the surface energy consists of disperse and polar interactions. The polar interactions are caused by dipole-dipole interactions and hydrogen bonds. The dispersive interactions are caused by van der Waals interactions. For the measurement of the contact angle the OCA Contact Angle System from DataPhysics was used. The test liquids were deionized water, diiodmethane and ethylene glycol. The surface energy of the test sample can be calculated from the contact angle and the surface tension of the test liquids. The contact angle of every liquid was measured ten times and a mean value was calculated.

\subsection{Three-point bending}

One import mechanical requirement for a wiring board is the stiffness of the material. In order to increase the reliability of electronic components and conducting paths, the materials should be used for different applications depending on their level of stiffness. Materials with a high stiffness should be used for stiffness applications and materials with a low stiffness for flexible applications. Therefore the three-point bending test was applied to determine the bending strength and to determine the possible application field of the substrate. Three-point bending tests according to DIN EN ISO 14125 standards for fibre-reinforced plastics were performed.

With this measuring method the stress-strain behavior could be determined and subsequently the E-modulus calculated. The measurement setup consist of two supports with an radius of $R_{2}$, and a distance $L$ (span), which are arranged parallel. The compression is placed in the center between the supports and has a radius of $\mathrm{R}_{1}$. The test specimen is located between the supports and the compression.

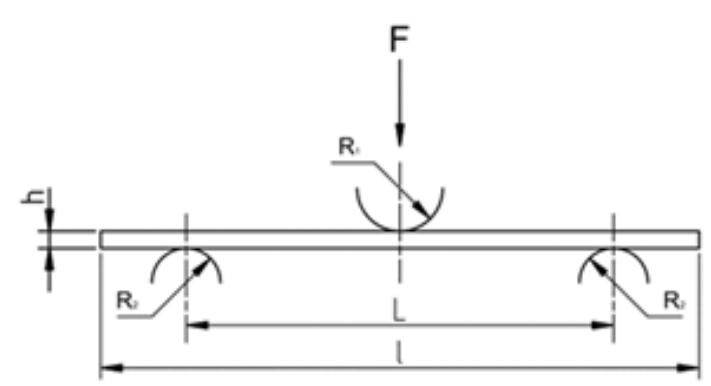

Fig. 1 Schematic of three-point bending test setup

The compression applies a certain force onto the substrate. For the samples a thickness h of $2 \mathrm{~mm}$ was defined. According to DIN EN ISO 14125 the samples should have a width b of $25 \mathrm{~mm}$, the length 1 of $40 \mathrm{~mm}$ and the span $\mathrm{L}$ should be $32 \mathrm{~mm}$. The supports had a radius of $5 \mathrm{~mm}$. The bending speed was $0.0143 \mathrm{~mm} / \mathrm{s}$. To calculate the E-modulus the following formula has been applied

$$
E_{-} f=L^{\wedge} 3 /\left(4 b h^{\wedge} 3\right)(\Delta F / \Delta s)
$$

$\mathrm{F}$ is the applied force at $s^{\prime}$ and $s^{\prime \prime}, \mathrm{s}$ is the deflection at strain $\varepsilon^{\prime} f$ and $\varepsilon^{\prime \prime} f$ :

$$
\begin{aligned}
& s^{\prime}=\left(\varepsilon_{-} f^{\prime} L^{\wedge} 2\right) / 6 h \\
& s^{\prime \prime}=\left(\varepsilon_{-} f^{\prime \prime} L^{\wedge} 2\right) / 6 h
\end{aligned}
$$

\subsection{Dielectric Strength}

The electrical breakdown is the loss of insulating properties of the polymer because of electrical influence. In accordance to the dielectric strength the insulating ability of polymers can be concluded. The measurements were carried out according to IEC 60243. The measurement setup consists of a container filled with vegetable oil. In the middle of the container are two ball electrodes with a diameter of $20 \mathrm{~mm}$. Vertical and at the same axis between the electrodes the specimen with a geometry of $75 \times 75 \times 2 \mathrm{~mm}$ was mounted (Fig. 2). The voltage was continuously increased with a constant slew rate until breakthrough beginning at $0 \mathrm{~V}$.

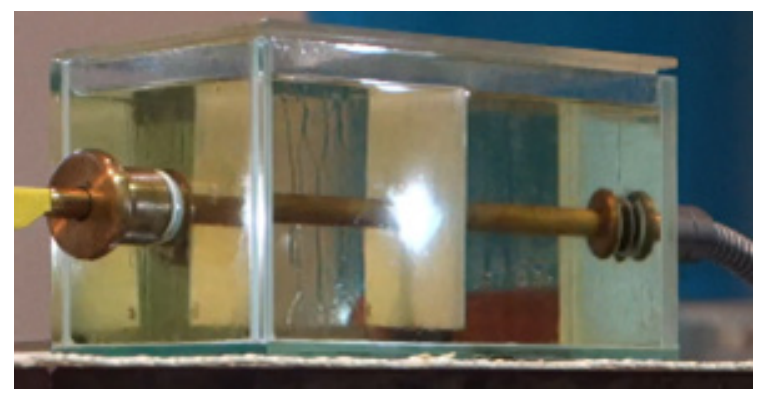

Fig. 2 Measurement setup to measuring the Dielectric Strength 
Polymers have good electrical insulating properties. These electrical insulating properties of materials can be described with the permittivity. The measurements have been performed according to IEC 60250 with a schering bridge method. The specimen is placed between the plates of a capacitor and DC voltage is applied. The reference is an air filled capacitor. The used specimen geometry is $150 \times 150 \times 2 \mathrm{~mm}$.

\subsection{Surface resistivity and Volume resistivity}

Additional electrical characteristics are surface resistivity and volume resistivity of polymer materials. These characteristic values are aimed at evaluating the insulation capability. The surface resistivity is the quotient of applied voltage between two electrodes and the current between these electrodes. Both electrodes are positioned on the same surface. The DC voltage is applied within a certain period of time. On the surface of the test specimen, which is level and coplanar, two circular, concentric plate electrodes with a diameter $\mathrm{d}_{1}$, distance between the ring electrode and the inner electrode $g$ and $p$ the circumference of electrode were positioned. Specific voltage and constant current determine the resistance value $\mathrm{R}_{\mathrm{OX}}$. For improved comparability, the specific surface resistivity $\sigma_{\mathrm{O}}$ is used [17].

$$
\begin{aligned}
& p=\pi\left(d_{1}+g\right) \\
& \sigma_{-} O=p / g \cdot R_{-} O X
\end{aligned}
$$

The volume resistivity $\rho_{\mathrm{D}}$ is the quotient of the applied voltage between two electrodes and the current between these electrodes. The electrodes with an area AE and RDX is the measured resistance are positioned on opposite sides of the polymer material [17].

$$
\begin{aligned}
& A_{-} E=\pi / 4 \cdot d_{-} 1^{\wedge} 2 \\
& \rho_{-} D=A_{-} E / h \cdot R_{-} D X
\end{aligned}
$$

where $\mathrm{h}$ is the thickness of specimen.

\subsection{Compatibility of PTFT}

For the application as a wiring board lead structures are needed. To realize this the polymer thick film technology was used. The screen-printer DEK 249 and the conductive paste DuPont 5015 were used. The curing took place in a heat cabinet. To measure the conductivity of an electrical conductive layer, the sheet resistance of a silver conductive paste on PLA/CA, FR4 and PU were compared. The sheet resistance is calculate in accordance to the following formula.
$R_{F}=R_{F X} \cdot b_{-} L / l_{-} L$

where $R_{F}$ is the sheer resistance, $R_{F X}$ is the measured resistance with the relation of the width of the wire $b_{L}$ and the length $\mathrm{l}_{\mathrm{L}}$. Because of the relatively low glass transition temperature of PLA a curing temperature of $80{ }^{\circ} \mathrm{C}$ was chosen for all substrate variants. This investigation is done to figure out whether a curing temperature of $80^{\circ} \mathrm{C}$ is sufficient for curing of silver conductive pastes.

\section{Investigations and results}

\subsection{Investigations of surface properties and mechanical properties}

\subsubsection{Roughness}

The standard material FR4 has a $\mathrm{Sa}=2.62 \mu \mathrm{m}$. All samples show higher roughnesses than FR4. The roughness of the PU compounds increases with higher CA content. The addition of CA to PLA leads to an increased roughness of the samples. It is interesting that this increase is already recognizable with low amounts of CA. A further increase of CA in the samples leads to a gradual decrease of the roughness. The decrease with higher CA content can be explained with the inhomogeneity of the samples. More CA fibres can be on the surface of the sample. A higher roughness suggests that the adhesive strength is better. This should be confirmed in further investigations. For PLA, less CA content is better for the processing to a wiring board.

\subsubsection{Surface energy}

The surface energy, the polar and dispersive interactions of the PLA and PU composites are shown in Table 1 and 2 respectively. It can be seen that the amount of added CA has no significant influence on the distribution of the surface

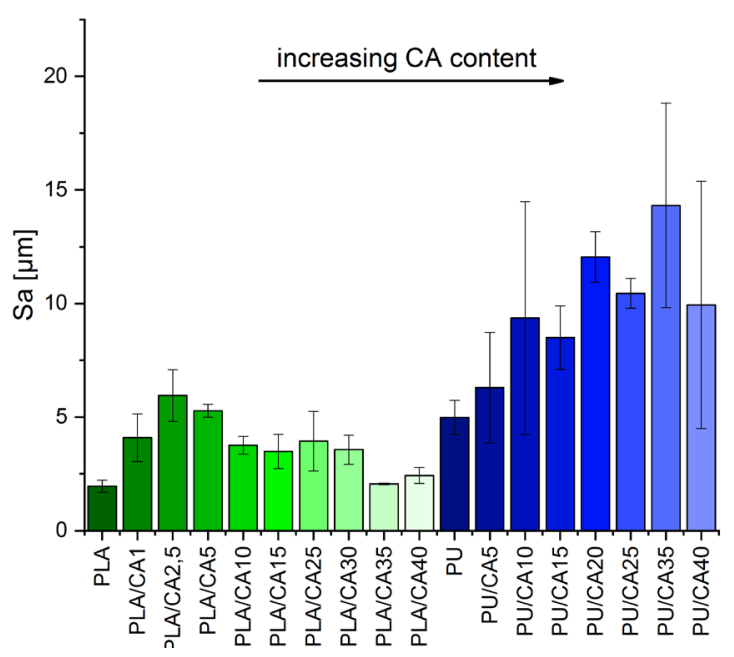

Fig. 3 Roughness (Sa) of PLA/CA and PU/CA composites 
Table 4 Surface energy, dispersive and polar interaction of PLA/CA composites

\begin{tabular}{lccc}
\hline Sample & $\begin{array}{c}\text { Surface } \\
\text { energy } \\
{[\mathrm{mN} / \mathrm{m}]}\end{array}$ & $\begin{array}{c}\text { Dispersive } \\
\text { interactions } \\
{[\mathrm{mN} / \mathrm{m}]}\end{array}$ & $\begin{array}{c}\text { Polar } \\
\text { interactions } \\
{[\mathrm{mN} / \mathrm{m}]}\end{array}$ \\
\hline PLA & $42.18 \pm 2.62$ & $34.24 \pm 2.19$ & $7.94 \pm 1.44$ \\
PLA/CA10 & $43.13 \pm 1.91$ & $38.19 \pm 1.37$ & $4.94 \pm 1.33$ \\
PLA/CA20 & $44.47 \pm 3.36$ & $38.65 \pm 2.75$ & $5.82 \pm 1.93$ \\
PLA/CA30 & $46.68 \pm 2.13$ & $44.54 \pm 1.98$ & $2.14 \pm 0.79$ \\
PLA/CA40 & $44.66 \pm 2.31$ & $40.37 \pm 1.95$ & $4.29 \pm 1.24$ \\
\hline
\end{tabular}

energy into polar and dispersive interactions. Rather the value of the surface energy and its distribution is influenced by the choice of matrix polymer. In both the PLA and PU composites the dispersive interactions outweigh the polar interactions. Which means that in both cases the van der Waals interactions have a greater influence on the surface energy than the different polar interactions. For a later lamination process of the polymer with copper foil it is important to know the surface energy and its distribution of the copper foil. Values of $34 \mathrm{mN} / \mathrm{m}$ for the surface energy, $28 \mathrm{mN} / \mathrm{m}$ for the dispersive interactions and $6 \mathrm{mN} / \mathrm{m}$ for the polar interactions of copper were found [17]. Because the magnitude and the distribution of the surface energies of the composites and copper are similar, the adhesion between copper and the polymers should benefit.

\subsubsection{E-Modulus}

Fig. 4 and 5 show the E-Modulus for the PLA composites and the PU composites respectively. The E-modulus of PLA decreased with increasing CA amount. Under the same condition, PU samples show a rising E-modulus with increasing $\mathrm{CA}$ amount. Both materials show an

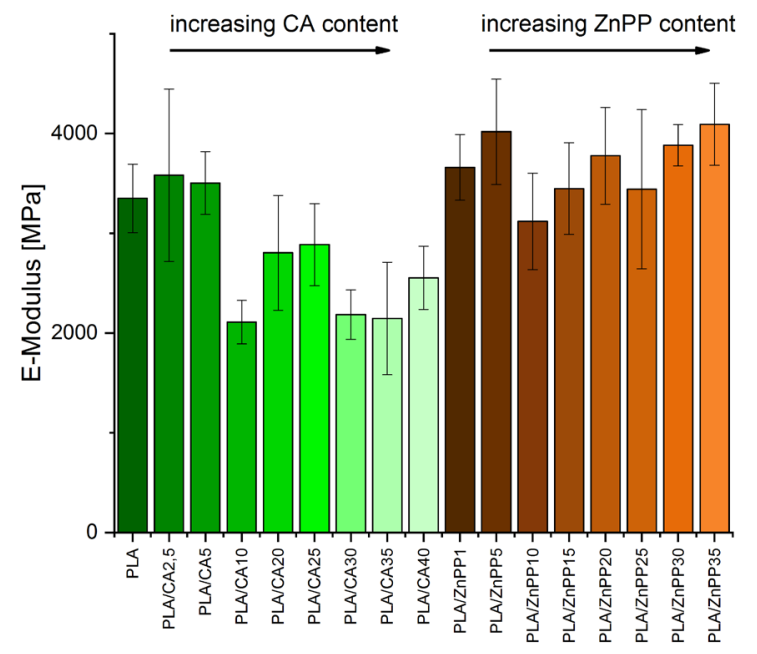

Fig. 4 E-Modulus of PLA/CA and PLA/ZnPP

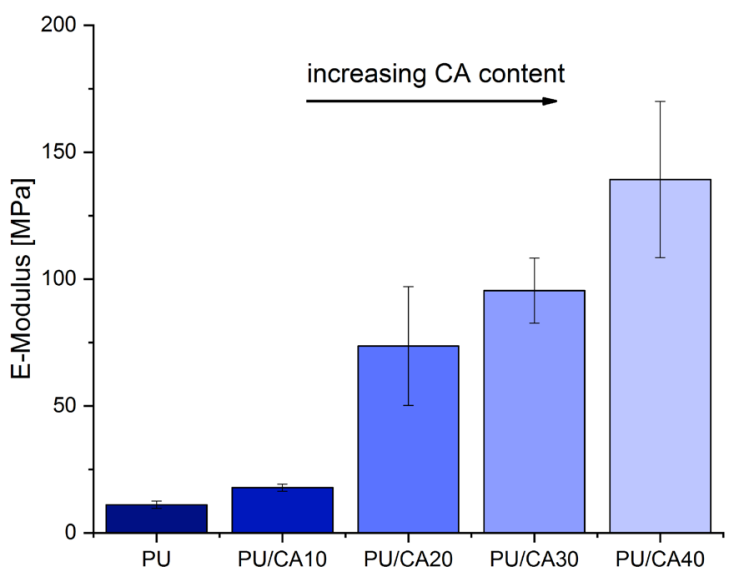

Fig. 5 E-Modulus of PU/CA composites

E-Modulus in different magnitudes. PLA demonstrates a good E-modulus for stiffness applications. From the sample PLA/CA10 forward variation of the E-modulus could be due to inhomogenities in the samples. During the production process it was observed that the viscosity of the compound increases significantly with the CA amount. This negative processability makes it more difficult to produce a homogenous compound. On the other hand, the E-Modulus of PU and its composites is significantly lower compared to PLA composites despite the addition of CA. The samples from PU/CA10 forward could be used as a flexible substrate. Here a similar aspect of inhomogeneity should be taken into account by interpretation of this data.

\subsection{Electrical properties}

\subsubsection{Dielectric strength}

Fig. 6 shows the dielectric strengths of the PLA composites. With different CA contents the dielectric strengths show nearly a constant behavior around $20 \mathrm{kV} / \mathrm{mm}$. The

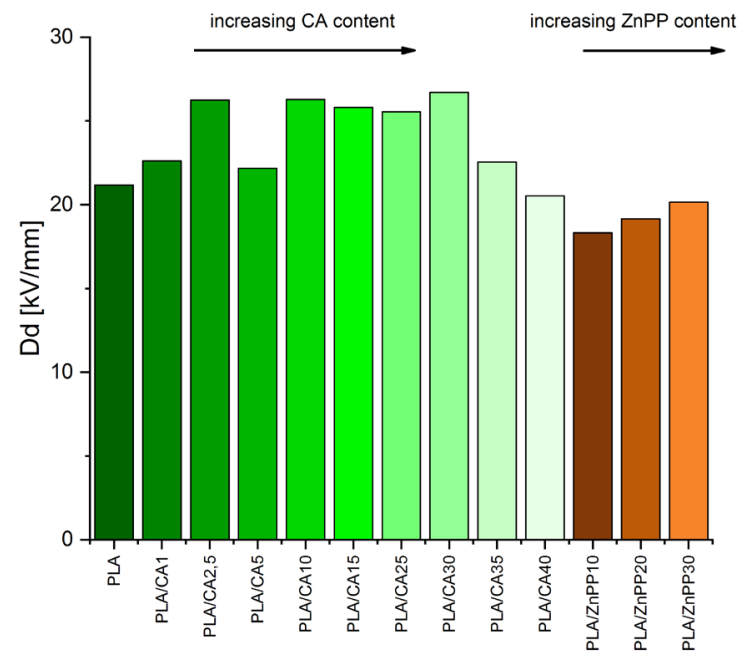

Fig. 6 Dielectric strength of PLA/CA and PLA/ZnPP composites 


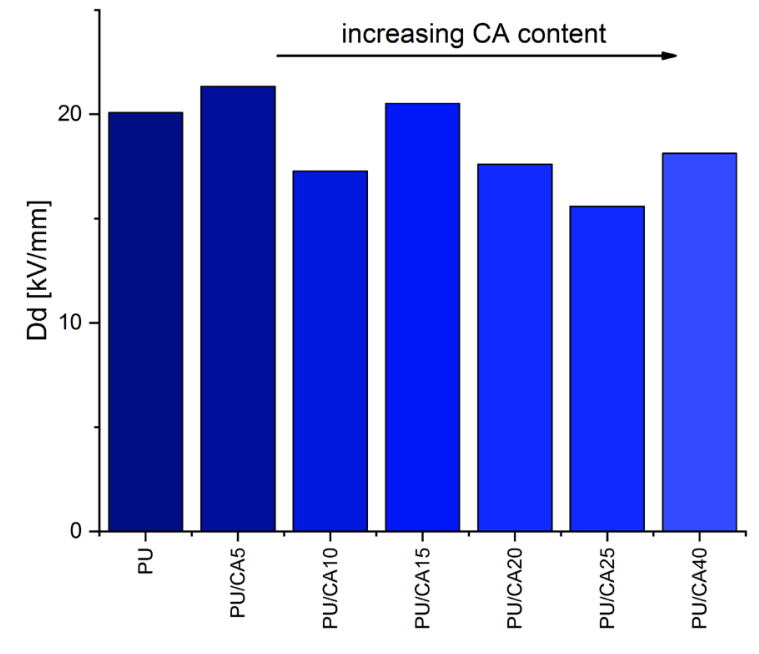

Fig. 7 Dielectric strength of PU/CA composites

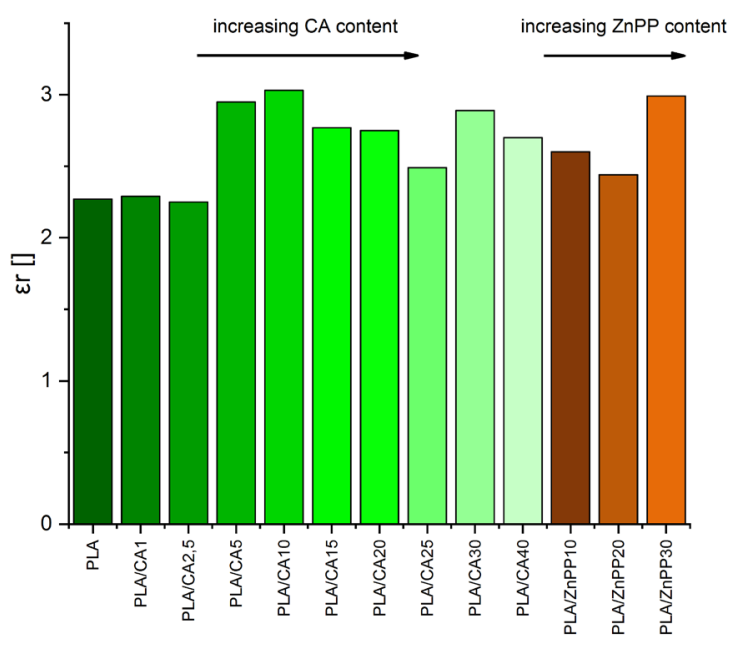

Fig. 8 Dielectric constant of PLA/CA and PLA/ZnPP composites deviations could be caused by the inhomogenities within the material. Because the samples were produced in lab scale inhomogeneities were unavoidable. In further investigations the effect should be FR4 shows a dielectric strength of $29 \mathrm{kV} / \mathrm{mm}$ and FR2 $19.7 \mathrm{kV} / \mathrm{mm}$. The values of PLA/CA are of similar magnitude compared to FR2 or even higher. The addition of ZnPP to PLA leads to a decrease of the dieclectric strenght.

For PU a similar trend is apparent. The variations may be caused by inhomogeneities and thus the unequal distribution of CA within the sample as well.

\subsubsection{Dielectric constant}

Fig. 8 shows the dielectric constant results of PLA CA and ZnPP composites. The first two PLA/CA samples with a very low CA content show no significant difference to pure PLA. From PLA/CA5 onwards the dielectric constant of the samples increases to a nearly constant value for different CA contents. But this can also be measurement errors. A similar effect is visible for PLA with ZnPP. The low permittivity indicates a negative loading of the material. The cause of the capacity in the material is the orientation polarization. For these substrate variations good results could be achieved. These results should be handled carefully because multiple measurements were not performed. FR4 shows a permittivity of 4.6.

\subsubsection{Surface resistivity and Volume resistivity}

Table 5 shows the measured surface and volume resistivity of selected PLA and PU composites as well as FR4.

For Interpretation, the magnitude is significant. Polymer materials need to have a resistivity of $>10^{\wedge} 12 \Omega$ or rather $>10^{\wedge} 12 \Omega / \mathrm{cm}$ to be insulating. The results of PLA composites are in the range between $10^{\wedge} 14$ and $10^{\wedge} 16$. PU composites are around $10^{\wedge} 15$. From that point of view both bio-based materials are suitable for wiring board material.

\subsection{Compatibility on PTFT}

Fig. 9 shows sheet resistance of silver paste on different substrates depending on the curing time. PU shows a more rapid decrease in resistance compared to PLA and FR4. This means that the curing temperature of $80{ }^{\circ} \mathrm{C}$ can be enough to cure a silver paste on PU substrates. The PLA composite shows better resistance values than FR4 as well. This suggests that at higher curing temperatures the conductive paste on PLA shows a similar good conductivity than on FR4. Nevertheless, the curing temperature of $80^{\circ} \mathrm{C}$ is not high enough for sufficient conductivity.

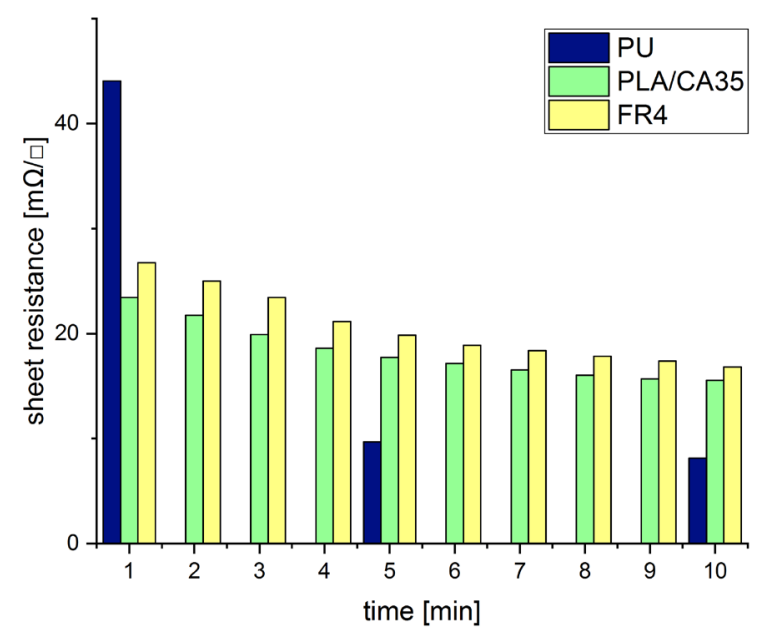

Fig. 9 Sheet resistance of the PLA/CA35, FR4 and PU 
Table 5 Surface and Volume resistivity of PLA composites and PU composites

\begin{tabular}{lcc}
\hline Sample & Surface resistivity $[\Omega]$ & Volume resistivity $[\Omega / \mathrm{cm}]$ \\
\hline PLA & $4 \cdot 10^{15}$ & $1 \cdot 10^{15}$ \\
PLA/CA1 & $7 \cdot 10^{15}$ & $5 \cdot 10^{16}$ \\
PLA/CA2,5 & $3 \cdot 10^{15}$ & $1 \cdot 10^{17}$ \\
PLA/CA5 & $3 \cdot 10^{16}$ & $1 \cdot 10^{17}$ \\
PLA/CA15 & $5 \cdot 10^{15}$ & $5 \cdot 10^{16}$ \\
PLA/CA25 & $1 \cdot 10^{15}$ & $3 \cdot 10^{16}$ \\
PLA/CA30 & $9 \cdot 10^{14}$ & $1 \cdot 10^{17}$ \\
PLA/CA35 & $4 \cdot 10^{15}$ & $2 \cdot 10^{17}$ \\
PLA/CA40 & $5 \cdot 10^{14}$ & $1 \cdot 10^{17}$ \\
PU & $4 \cdot 10^{14}$ & $1 \cdot 10^{16}$ \\
PU/CA35 & $2 \cdot 10^{14}$ & $2 \cdot 10^{15}$ \\
FR4 & $1 \cdot 10^{12}$ & $5 \cdot 10^{12}$ \\
\hline
\end{tabular}

Fig. 10 shows test prints on different substrate materials (PU, PU/CA35, PLA and PLA/CA35). All substrates show printable structures. It can also be seen that with increasing CA content the structures were more inexact, because of the increasing roughness of the materials. With a higher CA content, more CA fibers are on the surface. Therefore, it can be concluded that lower CA contents are better suited for screen-printing.

\subsection{Flame protection}

The fire behavior of the samples was tested with the help of a self constructed chimney that was build according to DIN 53438. The samples were fixed between two metal
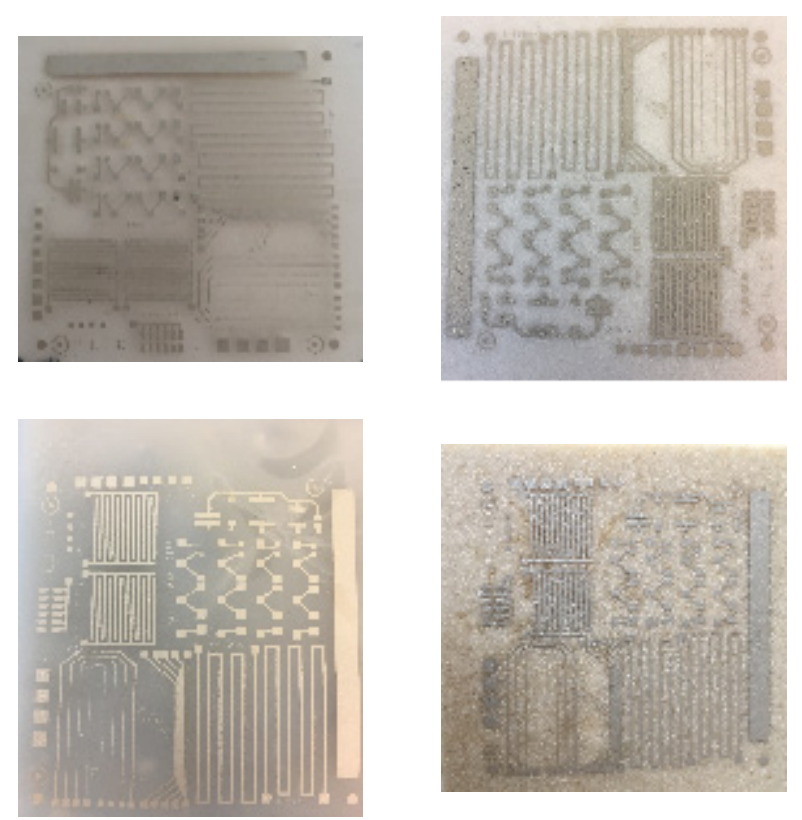

Fig. 10 Screen printing on PU, PU/CA35, PLA and PLA/CA35 plates inside the chimney. Through a hole in the wall a burner was positioned so the flame reaches only the bottom of the sample. After an inflammation of $3 \mathrm{~s}$ and after $7 \mathrm{~s}$ the observations of the samples were noted. Following this treatment an additional flame treatment was performed.

Table 6 shows the observations of the flame retardancy test. It was observed that the PLA samples start burning with melted substrate dropping down immediately after coming in contact with the burner flame. The conclusion that PLA is a fast burning material was confirmed [5]. CA fibers are easily flammable as well. Therefore, the addition of a flame retardant into the polymer is necessary to avoid easy burning. It was observed that the samples with ZnPP did not start burning during this test. Which meant a significant improvement compared to the pure PLA and the PLA/CA composite. Therefore the flame retardant effect that is necessary in PCB materials could be achieved with the addition of $\mathrm{ZnPP}$ into PLA.

\section{Conclusion}

This paper deals with the influence of CA and ZnPP as additives on the properties of PLA and PU. The roughness investigation lead to the conclusion that the roughness can already be increased with a small amount of CA. Especially the PU/CA samples showed a significant influence of the amount of CA on the E-modulus. Even though the E-modulus of PU composites increases with the amount of CA, the E-modulus of the composites was still low enough for them to be used for flexible applications. The E-modulus of PLA composites suggests the use in rigid applications. The results of different electrical properties show that these additives have no significant influence on them. The magnitudes of the electrical properties are similar to the properties of the FR2 material. The applicability of PTFT on the samples was tested and showed that the use is appropriable for both the PU and PLA substrates. PU samples with lower amounts of CA show better structure precision than with higher amount. Though the curing temperature of $80{ }^{\circ} \mathrm{C}$ needs to be increased in case of PLA. Testing the flame retardancy lead to the conclusion that the addition of a flame retardant like ZnPP is necessary. Overall both PLA and PU composites are suitable

\begin{tabular}{ll}
\multicolumn{2}{c}{ Table 6} \\
\hline PLA/ & Results of flame retardancy test observation. \\
CA-composites & $\begin{array}{l}\text { Material is burning with a lot of material } \\
\text { dripping from the substrate during the fire test }\end{array}$ \\
\hline PLA/ZnPP & $\begin{array}{l}\text { Material is not burning, only smoulders with } \\
\text { less material loss }\end{array}$ \\
\hline
\end{tabular}


for screen printing applications. The used additives lead to an improvement of the samples properties. PU composites of lower CA content should be preferred because the fibrous character of the CA negatively influences the quality of screen printing. Further investigations should include a method to increase the temperature stability. Additional

\section{References}

[1] Hegde, V. J., Gallot-Lavallée, O., Heux, L. "Overview on Thermal and Electrical Properties of Biodegradable Polymers"", In: 2015 IEEE $11^{\text {th }}$ International Conference on the Properties and Application of Dielectric Materials (ICPADM), Sydney, NSW, Australia, 2015, pp. 540-543.

https://doi.org/10.1109/ICPADM.2015.7295328

[2] Staat, A., Hohlfeld, T., Standau, T., Weimann, I., Bauer, R., Harre, K. "Substrates based on renewable resources for printed circuit boards", In: $37^{\text {th }}$ International Spring Seminar on Electronics Technology (ISSE), Dresden, Germany, 2014, pp. 50-53. https://doi.org/10.1109/ISSE.2014.6887560

[3] Staat, A., Vogt, M., Harre, K., Bauer, R. "Effect of Incorporation of Different Additives in Sustainable Polymers on Selected Electrical and Mechanical Properties", In: $201538^{\text {th }}$ International Spring Seminar on Electronics Technology (ISSE), Eger, Hungary, 2015, pp, 21-25. https://doi.org/10.1109/ISSE.2015.7247954

[4] Géczy, A., Nagy, D., Hajdu, I., Kmetty, Á., Szolnoki, B. "Investigating Mechanical Performance of PLA and CA Biodegradable Printed Circuit Boards", In: 2015 IEEE 21 th $^{\text {th }}$ International Symposium for Design and Technology in Electronic Packaging (SHTME), Brasov, Romania, 2015, pp. 45-49. https://oi.org/10.1109/SIITME.2015.7342293

[5] Mattana, G., Briand, G., Marette, A., Vásquez Quintero, A., de Rooij, N. F. "Polylactic acid as a biodegradable material for all-solution-processed organic electronic devices", Organic Electronics, 17, pp. 77-86, 2015. https://doi.org/10.1016/j.orgel.2014.11.010

[6] Vásquez Quintero, A., Frolet, N., Märki, D., Marette, A., Mattana, G., Briand, D., de Rooij, N. F. "Printing and encapsulation of electrical conductors on polylactic acid (PLA) for sensing applications", In: 2014 IEEE 27 $7^{\text {th }}$ International Conference on Micro Electro Mechanical Systems (MEMS), San Francisco, CA, USA, 2014, pp. 532-535.

https://doi.org/10.1109/MEMSYS.2014.6765695

[7] Haroon, Ullah, S., Flint, J. A. "Electro-textile based wearable patch antenna on biodegradable polylactic acid (PLA) plastic substrate for $2.45 \mathrm{GHz}$, ISM band applications", In: 2014 International Conference on Emerging Technologies (ICET), Islamabad, Pakistan, 2014, pp. 158-163. https://doi.org/10.1109/ICET.2014.7021036

[8] Oi, T., Shinyama, K., Fujita, S. "Electrical Properties of HeatTreated Polylactic Acid", Electrical Engineering in Japan, 180(1), pp. 1-8, 2012.

https://doi.org/10.1002/eej.21272 parameters that are relevant for the application of the materials as wiring boards should be tested.

\section{Acknowledgement}

The project presented in this article is supported by the European Social Fonds (ESF).

[9] Hikosaka, S., Ishikawa, H., Ohki, Y. "Effects of Crystallinity on Dielectric Properties of Poly(L-lactide)", Electronics and Communications in Japan, 94(7), pp. 217-222, 2011. https://doi.org/10.1002/ecj.10348

[10] Tao, J., Ding, D., Cong, S., Tuerdi, T., Yan, L. "Enhanced mechanical properties and flame retardancy of short jute fiber/poly(lactic acid) composites with phosphorus-based compound", Science China Technological Sciences, 60(11), pp. 1716-1723, 2017. https://doi.org/10.1007/s11431-016-9009-1

[11] Woo, Y., Cho, D. "Effect of aluminium trihydroxide on flame retardancy and dynamic mechanical and tensile properties of kenaf/poly(lactic acid) green composites", Advanced Composite Materials, 22(6), pp. 451-464, 2013. https://doi.org/10.1080/09243046.2013.843831

[12] Langat, H.K., Dimitrov, K., Herzog, M., Muchiri, P., Keraita, J. "Investigating the Thermal and Mechanical Performance of Polylactic Acid (PLA) Reinforced with cellulose, wood fibers and Copolymer", International Organization of Scientific Research (IOSR) Journal of Polymer and Textile Engineering (IOSR-JPTE), 4(3), pp. 25-32, 2017. https://doi.org/10.9790/019X-04032532

[13] Shukor, F., Hassan, A., Saiful Islam, M., Mokhtar, M., Hasan, M. "Effect of ammonium polyphosphate on flame retardancy, thermal stability and mechanical properties of alkali treated kenaf fiber filled PLA biocomposites", Materials \& Design, 54, pp. 425-429, 2014. https://doi.org/10.1016/j.matdes.2013.07.095

[14] Ishikawa, T., Maki, I., Takeda, K. "Flame Retardancy of Poly(butylene tereohthalate) Blended with Phosphorous Compounds", Journal of Applied Polymer Science, 92(4), pp. 2326-2333, 2004. https://doi.org/10.1002/app.20228

[15] Staat, A., Mende, R., Schumann, R., Harre, K., Bauer, R. "Investigation of wiring boards based on biopolymer substrates", In: 2016 39th International Spring Seminar on Electrical Technology (ISSE), Pilsen, Czech Republic, 2016, pp. 77-82. https://doi.org/10.1109/ISSE.2016.7563165

[16] European Committee for Standardization "DIN IEC 60093:199312 Prüfverfahren für Elektroisolierstoffe; spezifischer Durchgangswiderstand und spezifischer Oberflächenwiderstand von festen, elektrisch isolierenden Werkstoffen" (Methods of test for insulating materials for electrical purposes; volume resistivity and surface resistivity of solid electrical insulating materials), CEN, 1993. (in German)

[17] Barriga, J., Fernández-Diaz, B., Juarros, A., Ahmed, S. I.-U., Arana, J. L. "Microtribological analysis of gold and copper contacs", Tribology International, 40(10-12), pp. 1526-1530, 2007. https://doi.org/10.1016/j.triboint.2007.01.009 